\title{
Differential Reaction-Rate Methods in Flow Analysis
}

\author{
Milton K. Sasaki, Simone Vicente ${ }^{\S}$, Viviane Grassi ${ }^{\circledR}$ and Elias A.G. Zagatto*
}

Center for Nuclear Energy in Agriculture, University of Sao Paulo, 13400-970 Piracicaba SP, Brazil

\begin{abstract}
Simultaneous determinations exploiting the rates of reactions of different analytes with a common reagent, often referred to as differential kinetic analysis, is efficiently implemented in the flow analyser. To this end, specific strategies for pumping, commuting and/or detecting have been proposed. This review critically discusses the potentialities, limitations and application ranges of the different flow systems designed to accomplish differential reactionrate methods, with emphasis to those involving spectrophotometric and luminometric detection.
\end{abstract}

Keywords: Flow analysis, differential reaction-rate methods, differential kinetic analysis, review, simultaneous determinations.

\section{INTRODUCTION}

An efficient way to accomplish multi-component analysis is to exploit the different rates at which two or more chemical species interact with a common reagent system [1], and the related methods are often referred to as differential reaction-rate methods. Catalytic methods where the analytes are the catalysts and the rate of the indicator reaction is the measurement basis are also included in this context. Differential reaction-rate methods constitute themselves as an effective solution to a crucial analytical problem: the resolution of mixtures of closely related species [2].

These methods require a reproducible management of the solutions involved and a rigid timing control, and these features are inherent to flow analysis [3]. Implementation in the flow analyzer is then straightforward, as demonstrated in the landmark article by Dahl et al. who designed a flowinjection system for the spectrophotometric determination of magnesium and strontium [4]. The method relied on the different dissociation rates of the $\mathrm{Mg}(\mathrm{II})$ and $\mathrm{Sr}$ (II) trans-1,2diaminocyclohexanetetraacetate complexes under acidic conditions; $\mathrm{Cu}$ (II) was used as scavenger. Since then, and especially during the eighties and nineties, the availability of flow-based analytical procedures involving differential reaction-rate methods has been increasing, and specific manifold architectures have been proposed [5].

In most applications, the required time-dependent measurements are performed on different portions of the flowing sample, which are subjected to slight different handling conditions. Variations in sample dispersion, as well as in temperature, $\mathrm{pH}$ or ionic strength of the reaction medium, may occur during the time interval elapsed between measurements. In these situations, the approach could be

\footnotetext{
*Address correspondence to this author at the Center for Nuclear Energy in Agriculture, University of Sao Paulo, 13400-970 Piracicaba SP, Brazil;

Tel: +55 0193429 4650; Fax: +55 0193429 4610;

E-mail: ezagatto@cena.usp.br

'Present Address: "Luiz de Queiroz" College of Agriculture, University of Sao Paulo, Piracicaba SP, Brazil.

"Present Address: Agribusiness National Nanotechnology Laboratory, Embrapa Instrumentation, S. Carlos SP, Brazil.
}

considered as a pseudo differential kinetic analysis. On the other hand, better adherence to IUPAC definition [1] is noted when a single portion of the sample zone is halted in the detector and the time-based variation in measurement is considered as the measurement basis. For didactic purposes, the expressions pseudo differential kinetic analysis and derived ones are not used in this text.

In some applications, the conditions associated to each measurement can be modified by adding different reagents, and the spectrophotometric flow-injection determination of molybdenum and tungsten in alloys [6] can be selected as an example: the sample was inserted twice and a citric acid stream was added to only one of the established sample zones in order to minimise the tungsten contribution to the analytical signal. Applications involving solid bleaching or extractions [7] and/or electrochemical detectors relying on kinetic aspects (e.g. anodic stripping voltammetry [8]) usually exploit an ordinary flow system for monitoring purposes, and reaction-rate methods are not exploited. These applications are then not considered in this present monograph.

The strategies carried out with the stopped-flow analyser $[9,10]$ are relevant for monitoring fast analytical systems. These analysers are compatible with very short (down to $\mu \mathrm{s}$ ) time intervals, provide effective stopped-flow mixing and include modern detectors [11]. However, they have been scarcely used in routine large scale analysis and do not constitute themselves as typical flow analysers. A deeper discussion of these analysers falls then outside the scope of this review.

\section{GENERAL ASPECTS}

Some conditions should be met for implementing differential reaction-rate methods:

i) The concentration of the formed chemical species to be quantified, $\left[\mathrm{P}_{\mathrm{A}}\right]$, should be proportional to the concentration of the analyte, $[\mathrm{A}]$ associated with that species. As the reagent is present in excess, Eq. (1) holds for the involved pseudo first order reaction, providing that the time interval for reaction development is restricted. Thus:

$$
\left[\mathrm{P}_{\mathrm{A}}\right]=\mathrm{k}[\mathrm{A}]
$$


where $\mathrm{k}=$ pseudo first order rate constant [2].

ii)

For two or more analytes, $\mathrm{A}_{i}$, mutual or synergistic effects on the reaction rates should ideally be absent. Eq. (1) can then be expanded to Eqs 2 and 3:

$$
\begin{aligned}
& {\left[\mathrm{P}_{\mathrm{A} 1}\right]+\left[\mathrm{P}_{\mathrm{A} 2}\right]=\mathrm{k}_{\mathrm{A} 1}\left[\mathrm{~A}_{1}\right]+\mathrm{k}_{\mathrm{A} 2}\left[\mathrm{~A}_{2}\right]} \\
& \Sigma\left[\mathrm{P}_{\mathrm{i}}\right]=\Sigma\left(\mathrm{k}_{\mathrm{i}}\left[\mathrm{A}_{\mathrm{i}}\right]\right)
\end{aligned}
$$

In general, $\mathrm{P}_{\mathrm{A} 1}$ is essentially similar to $\mathrm{P}_{\mathrm{A} 2}$ in relation to the analytical property to be measured. This means additivity of the analytical signals related to $\mathrm{P}_{\mathrm{A} 1}$ and $\mathrm{P}_{\mathrm{A} 2}$. In some applications (e.g. catalytic analytical procedures), $\mathrm{P}_{\mathrm{A} 1}$ and $\mathrm{P}_{\mathrm{A} 2}$ are the same chemical species.

iii) The $\left(\mathrm{k}_{\mathrm{i}}\left[\mathrm{A}_{\mathrm{i}}\right]\right)$ terms should be as dissimilar as possible. For good discrimination, the $\left(\mathrm{k}_{1}\left[\mathrm{~A}_{1}\right]\right) /\left(\mathrm{k}_{2}\left[\mathrm{~A}_{2}\right]\right)$ ratio should be normally $>3$; lower ratios are feasible by exploiting advanced mathematical algorithms [2].

Different approaches have been used for obtaining the analyte concentrations:

If two analyte determinations are aimed at and the $\left(\mathrm{k}_{\mathrm{i}}\right.$ $\left.\left[\mathrm{A}_{\mathrm{i}}\right]\right)$ terms are very dissimilar from each other or, in other words, if the reaction development is quantitative for one analyte and relatively slow for the other, the measurement performed immediately after reagent additions, M', reflects the concentration of one analyte whereas the temporal increase in measurement $[\Delta \mathrm{M} "=\mathrm{f}(\mathrm{t})]$ is considered for estimating the concentration of the other analyte. To this end, the slope of the (M" $v s \mathrm{t}$ ) function, is usually recorded and taken into account.

If two analyte determinations are aimed at and relatively high $\left(\mathrm{k}_{1}\left[\mathrm{~A}_{1}\right]\right) /\left(\mathrm{k}_{2}\left[\mathrm{~A}_{2}\right]\right)$ ratio are involved, two measurements ( $M$ ' and $\mathrm{M}^{\prime}$ ) are generally performed at different pre-set time intervals. As both analytes contribute to these measurements, two equations are obtained:

$\mathrm{M}^{\prime}=\mathrm{k}^{\prime}{ }_{1}\left[\mathrm{~A}_{1}\right]+\mathrm{k}_{2}{ }_{2}\left[\mathrm{~A}_{2}\right]$

$M "=k{ }_{1}\left[A_{1}\right]+k^{\prime \prime}{ }_{2}\left[A_{2}\right]$

where $\mathrm{k}^{\prime}$ and $\mathrm{k}$ ' = proportionality constants related to $\mathrm{M}^{\prime}$ and M".

As the analyte concentrations are gathered by solving Eqs 4 and 5, the approach has been referred to as the proportional equation method [2].

More than two measurements performed at different elapsed times can be considered, resulting in a larger number of equations to be solved. To this end, matrix calculations are generally required. Expansion of the proportional equation method is worthwhile for improving the numeric stability [12] and/or for multi-analyte determinations [13]. The approach however has been scarcely used in flow analysis probably because of the limitations associated with the $\left(\mathrm{k}_{\mathrm{i}}\left[\mathrm{A}_{\mathrm{i}}\right]\right)$ values.

If two or more analyte determinations are aimed at and/or the $\left(\mathrm{k}_{\mathrm{i}}\left[\mathrm{A}_{\mathrm{i}}\right]\right) /\left(\mathrm{k}_{\mathrm{j}}\left[\mathrm{A}_{\mathrm{j}}\right]\right)$ involved ratios constitute themselves as limiting factors in kinetic discrimination, several measurements are performed and chemometric tools such as e.g. principal component regression [14], partial least squares [15] or artificial neural networks [16] are required. A deeper presentation of these statistical tools is outside the scope of this monograph. The reader should be oriented towards specific texts such as e.g. Refs [17-19].

\section{IMPLEMENTATION IN FLOW ANALYSIS}

For implementing differential reaction-rate methods in flow analysis, strategies involving specific conditions for pump operation (A - Table 1), special manifold architectures (B - Table 1) and/or a more complete exploitation of the recorded signals ( $\mathrm{C}$ - Table 1 ) have been carried out, as discussed further.

\subsection{Specific Pump Operating Conditions}

The fluid propeller device - usually a peristaltic or a syringe pump - is operated to permit the delivered stream to be either pumped or halted during pre-set periods [20]. Alternatively, the pump can be continuously operated and stream halting is accomplished by resorting from commutation [21].

During the GO period, the sample is inserted into the analytical path and the required reagent solutions are in-line added (Fig. 1). When the sample zone is passing through the detector, the pump is switched off, allowing the fluid element associated with the analytical readouts to be halted inside the detector. During the STOP period, successive measurements are obtained, each one related to a given yet known time interval. The (analytical signal $v s$ time) function is then gathered. Thereafter, the pump is switched on again, restarting the flow, discarding the sample zone and inserting the next sample to be similarly handled.

The manifold architecture is designed as an ordinary flow system. Special attention should be given to the dimensioning of the main reactor and of the sample inserted volume, as these parameters play an additional role, namely to minimise carry-over. The inner volume of the reactor plus the front portion of the sample zone should be enough for properly washing the analytical path before stopping the handled sample inside the flow through detector. This aspect was highlighted in the spectrophotometric determinations of chlorpyrifos and carbaryl in commercial formulations [22]. Absorbance values referred to two different reaction times and two different wavelengths were taken into account and the proportional equation method was applied. Other applications involving specific pump operating conditions, some of them exploiting other approaches for gathering the analytical results, are presented in Table $\mathbf{1}$.

Implementation of these analytical procedures is accomplished in close adherence to IUPAC definition of differential reaction-rate methods [1], as the only parameter undergoing variations during the STOP period is the time interval available for reaction development. A noteworthy characteristic is that only one sample insertion is required. Moreover, the reagent solutions are not wasted during the STOP period. The need for successive ON/OFF pump switching that may limit the pump lifetime is however a shortcoming. In spite of the low versatility of the flow system and the possibility of the analytical signal surpass the concentration dynamic range, flow systems relying on ON/OFF pump switching are mostly applied. 
Table 1. Selected Applications

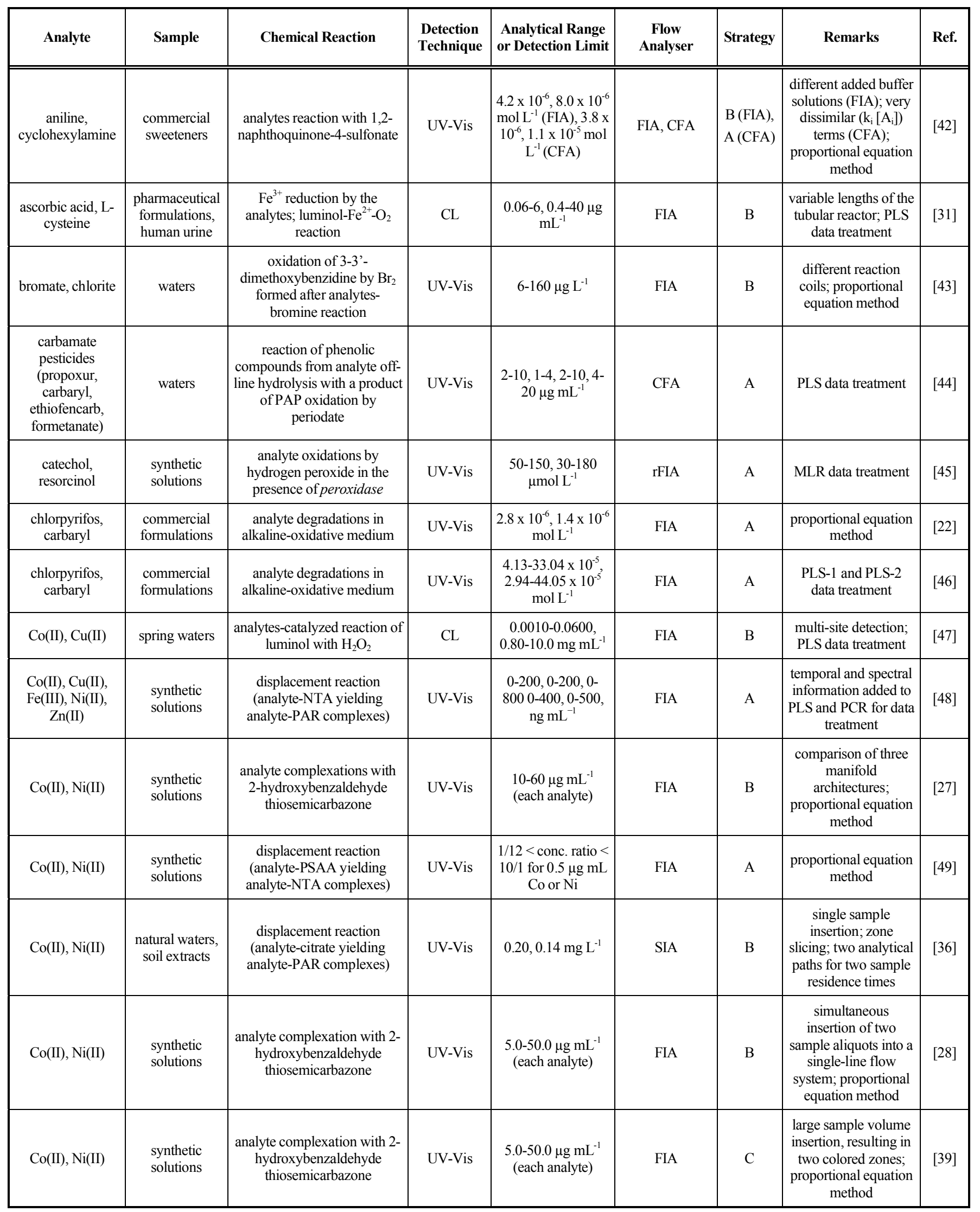


(Table 1) contd....

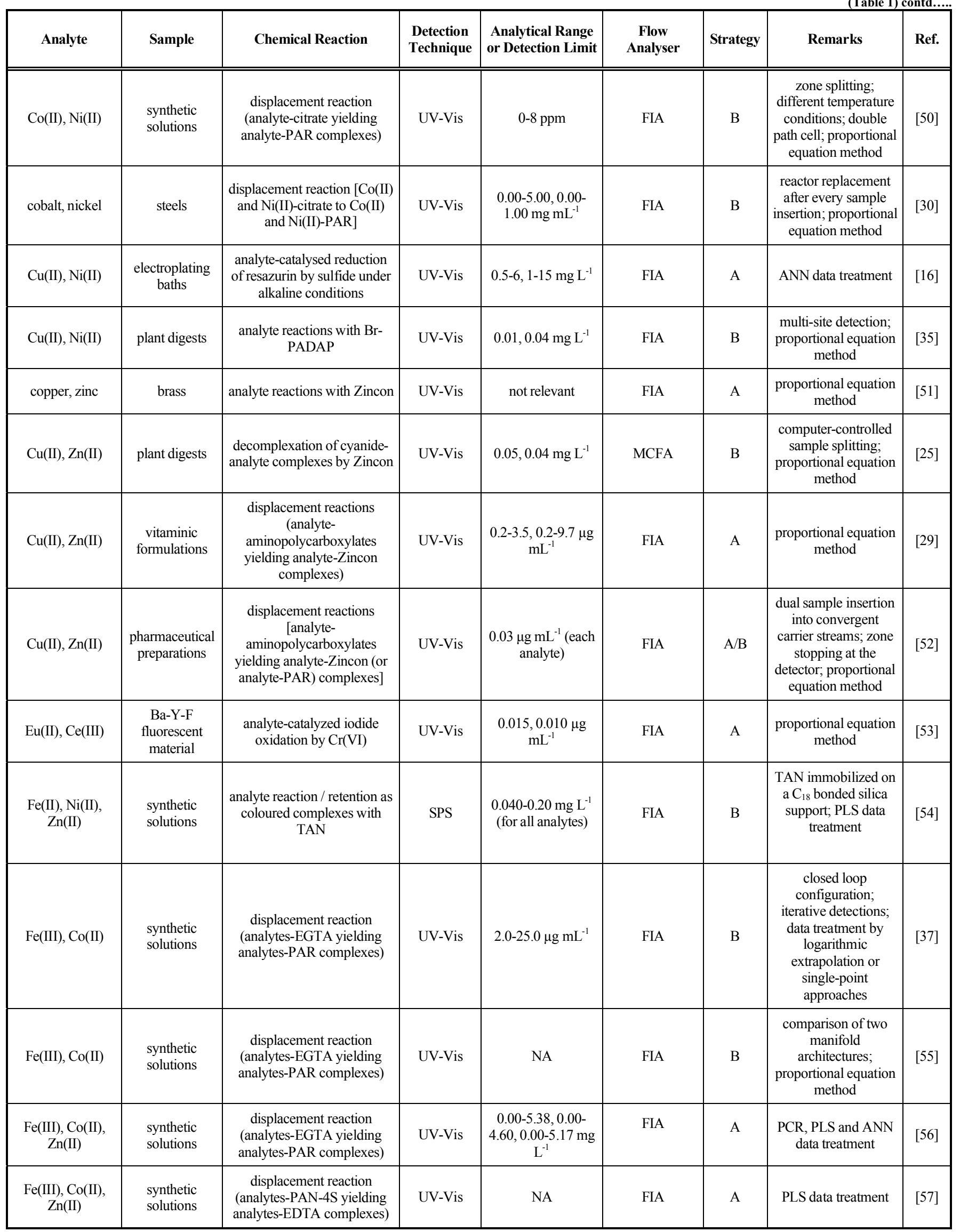




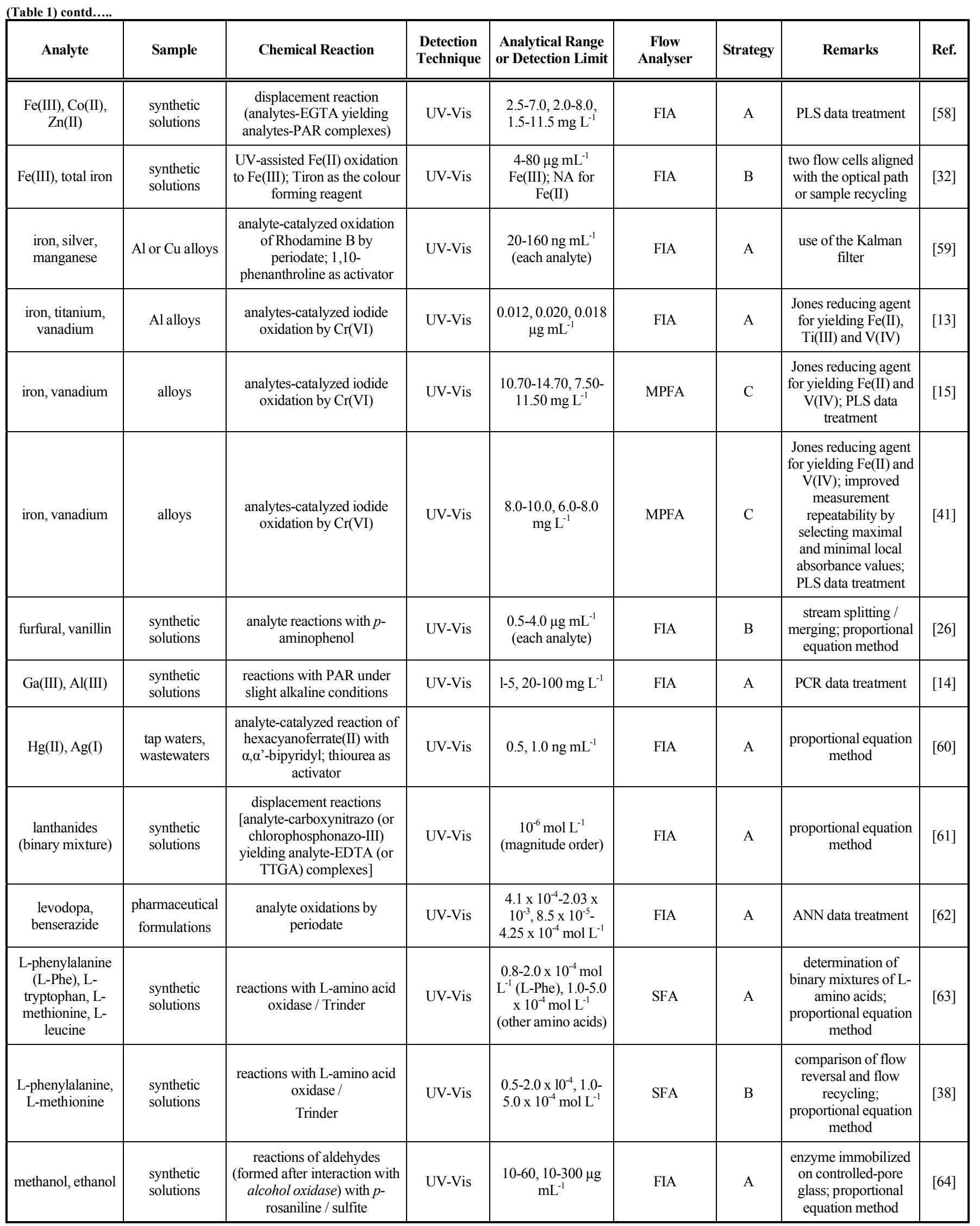


(Table 1) contd....

\begin{tabular}{|c|c|c|c|c|c|c|c|c|}
\hline Analyte & Sample & Chemical Reaction & $\begin{array}{l}\text { Detection } \\
\text { Technique }\end{array}$ & $\begin{array}{c}\text { Analytical Range } \\
\text { or Detection Limit }\end{array}$ & $\begin{array}{c}\text { Flow } \\
\text { Analyser }\end{array}$ & Strategy & Remarks & Ref. \\
\hline $\mathrm{Mg}(\mathrm{II}), \mathrm{Ca}(\mathrm{II})$ & $\begin{array}{l}\text { synthetic } \\
\text { solutions }\end{array}$ & $\begin{array}{l}\text { dissociations of the analytes- } \\
\text { cryptand ( } 2.2 .1) \text { complexes; } \\
\text { sodium ions as scavenger }\end{array}$ & $\mathrm{UV}-\mathrm{Vis}$ & $\begin{array}{l}2.00 \times 10^{-4}-1.00 \mathrm{x} \\
10^{-3} \mathrm{~mol} \mathrm{~L}^{-1}(\mathrm{each} \\
\text { analyte })\end{array}$ & FIA & B & $\begin{array}{l}\text { two serial flow- } \\
\text { through detectors; } \\
\text { proportional equation } \\
\text { method }\end{array}$ & [33] \\
\hline $\mathrm{Mg}(\mathrm{II}), \mathrm{Ca}(\mathrm{II})$ & $\begin{array}{l}\text { synthetic } \\
\text { solutions }\end{array}$ & $\begin{array}{l}\text { dissociations of the analytes- } \\
\text { cryptand (2.2.2) complexes; } \\
\text { reaction of the released } \\
\text { analytes with phthalein } \\
\text { complexone }\end{array}$ & UV-Vis & $\begin{array}{l}4.00-20.00 \times 10^{-5} \\
\text { mol L-1 (each } \\
\text { analyte) }\end{array}$ & FIA & A & MLR data treatment & {$[65]$} \\
\hline $\operatorname{Mg}(\mathrm{II}), \operatorname{Sr}(\mathrm{II})$ & $\begin{array}{l}\text { synthetic } \\
\text { solutions }\end{array}$ & $\begin{array}{l}\text { dissociations of the analytes- } \\
\text { CDTA complexes; cupric } \\
\text { ions as scavenger }\end{array}$ & UV-Vis & $\begin{array}{l}2.00 \times 10^{-4}-1.60 \mathrm{x} \\
10^{-3} \mathrm{~mol} \mathrm{~L}^{-1}(\mathrm{each} \\
\text { analyte })\end{array}$ & FIA & B & $\begin{array}{l}\text { two serial flow- } \\
\text { through detectors; } \\
\text { proportional equation } \\
\text { method }\end{array}$ & [4] \\
\hline $\operatorname{Mg}(\mathrm{II}), \operatorname{Sr}(\mathrm{II})$ & $\begin{array}{l}\text { synthetic } \\
\text { solutions }\end{array}$ & $\begin{array}{l}\text { dissociation of the analytes- } \\
\text { cryptand ( } 2.2 .2) \text { complexes; } \\
\text { potassium ion as scavenger }\end{array}$ & $\mathrm{UV}-\mathrm{Vis}$ & $\begin{array}{l}4.00 \times 10^{-4}-2.00 \mathrm{x} \\
10^{-3} \mathrm{~mol} \mathrm{~L}^{-1}(\mathrm{each} \\
\text { analyte })\end{array}$ & FIA & B & $\begin{array}{l}\text { two serial detectors or } \\
\text { two sample aliquots } \\
\text { inserted into } \\
\text { converging carrier } \\
\text { streams; proportional } \\
\text { equation method; } \\
\text { applicable also to } \\
\text { Sr(II) and Ca(II) } \\
\text { determinations }\end{array}$ & {$[66]$} \\
\hline $\mathrm{Mn}(\mathrm{II}), \mathrm{Fe}(\mathrm{III})$ & $\begin{array}{l}\text { synthetic } \\
\text { solutions }\end{array}$ & $\begin{array}{l}\text { analyte-catalyzed oxidations } \\
\text { of salicylaldehyde } \\
\text { thiosemicarbazone by } \\
\text { hydrogen peroxide }\end{array}$ & $\mathrm{F}$ & $\begin{array}{c}40-600,40-500 \mathrm{ng} \\
\mathrm{mL}^{-1}\end{array}$ & FIA & B & $\begin{array}{c}\text { stream splitting / } \\
\text { merging; simplex } \\
\text { optimization; } \\
\text { proportional equation } \\
\text { method }\end{array}$ & {$[67]$} \\
\hline $\begin{array}{c}\text { organophosphorus } \\
\text { pesticides } \\
\text { (omethoate, } \\
\text { dichlorvos, } \\
\text { dipterex) }\end{array}$ & vegetables & $\begin{array}{l}\text { analyte oxidations by } \\
\text { peroxodisulphate; yielded } \\
\text { orthophosphate reacts with } \\
\text { molybdate / vanadate; } \\
\text { yielded } \\
\text { vanadomolybdophosphoric } \\
\text { acid oxidizes luminol }\end{array}$ & CL & $<1 \times 10^{-8} \mathrm{~g} \mathrm{~mL}^{-1}$ & CFA & A & $\begin{array}{l}\text { UV-radiation assisted } \\
\text { analytes oxidation; } \\
\text { ANN data treatment }\end{array}$ & {$[68]$} \\
\hline $\begin{array}{c}\text { phenolic } \\
\text { compounds } \\
\text { (resorcinol, } m- \\
\text { aminophenol, } o- \\
\text { cresol, phenol, } m \text { - } \\
\text { cresol) }\end{array}$ & waters & $\begin{array}{l}\text { analyte reactions with a } \\
\text { product of PAP oxidation by } \\
\text { periodate }\end{array}$ & UV-Vis & $2-9 \mu \mathrm{g} \mathrm{mL}^{-1}$ & CFA & A & PLS data treatment & [69] \\
\hline $\begin{array}{l}\text { pyridoxal, } \\
\text { pyridoxal 5- } \\
\text { phosphate }\end{array}$ & $\begin{array}{l}\text { synthetic } \\
\text { solutions }\end{array}$ & $\begin{array}{l}\text { analyte oxidations in the } \\
\text { presence of cyanide }\end{array}$ & $\mathrm{F}$ & $\begin{array}{c}2.5 \times 10^{-8}-1.0 \times 10^{-4} \\
\mathrm{~mol} \mathrm{~L}^{-1}(\text { each } \\
\text { analyte })\end{array}$ & FIA & B & $\begin{array}{l}\text { stream splitting / } \\
\text { merging; proportional } \\
\text { equation method }\end{array}$ & {$[70]$} \\
\hline $\begin{array}{l}\text { rifampicin, } \\
\text { isoniazid }\end{array}$ & $\begin{array}{l}\text { combined } \\
\text { pharmaceutical } \\
\text { formulations }\end{array}$ & $\begin{array}{l}\text { oxidations by } \mathrm{N}- \\
\text { bromosuccinimide under } \\
\text { alkaline conditions }\end{array}$ & $\mathrm{CL}$ & $\begin{array}{c}0.09-5.0,0.08-10.0 \\
\mu \mathrm{g} \mathrm{mL}\end{array}$ & CFA & A & ANN data treatment & [71] \\
\hline silicate, phosphate & $\begin{array}{l}\text { natural } \\
\text { waters }\end{array}$ & $\begin{array}{l}\text { oxidation of thiamine by the } \\
\text { heteropoly acids formed at } \\
\text { different rates }\end{array}$ & $\mathrm{F}$ & $\begin{array}{l}\text { 30-600 ng mL } \\
\text { (each analyte) }\end{array}$ & FIA & A & $\begin{array}{l}\text { proportional equation } \\
\text { method }\end{array}$ & {$[72]$} \\
\hline $\begin{array}{l}\text { uranium, } \\
\text { vanadium }\end{array}$ & phosphate ores & $\begin{array}{l}\text { analytes-catalyzed iodide } \\
\text { oxidation by } \mathrm{Cr}(\mathrm{VI})\end{array}$ & UV-Vis & $0-3.6,0-2.5 \mu \mathrm{g} \mathrm{mL}^{-}$ & FIA & A & $\begin{array}{l}\text { proportional equation } \\
\text { method }\end{array}$ & [73] \\
\hline $\mathrm{Zn}(\mathrm{II}), \operatorname{Hg}(\mathrm{II})$ & $\begin{array}{l}\text { synthetic } \\
\text { solutions }\end{array}$ & $\begin{array}{l}\text { reactions with } 5,10,15,20- \\
\text { tetrakis-(3-chloro-4- } \\
\text { sulfophenyl)porphine }\end{array}$ & UV-Vis & $\begin{array}{c}0-3.0,0-2.0 \mu \mathrm{g} \\
\mathrm{mL}^{-1}\end{array}$ & FIA & A & $\begin{array}{c}\text { zone merging; } \\
\text { proportional equation } \\
\text { method }\end{array}$ & [74] \\
\hline
\end{tabular}

UV-Vis = spectrophotometry; SPS = solid phase spectrometry; $\mathrm{CL}=$ chemiluminescence; F = fluorimetry; Br-PADAP = 2-(5-bromo-2-pyridylazo)-5-diethylaminophenol; CDTA = trans-1,2-diaminocyclohexanetetraacetic acid; EDTA = ethylenediamino tetraacetic acid; EGTA = ethylene glycol tetraacetic acid; NTA = nitrilotriacetic acid; PAN-4S = 1-(2pyridylazo)-2-naphthol-4-sulfonic acid; PAP = p-aminophenol; PAR = 4-(2-pyridylazo)resorcinol; PSAA = 2-(5-bromo-2-pyridylazo)-5-(N-propyl-N-sulfopropylamino) aniline; TAN = 1-(2-thiazolylazo)-2-naphthol; TTGA = triethylentetramine hexaacetate; SFA = segmented flow injection analyser; FIA = flow injection analyser; rFIA = reversal flow injection analyser; SIA $=$ sequential injection analyser; MCFA $=$ multi-commuted flow analyser; MPFA $=$ multi-pumping flow analyser; CFA $=$ unsegmented continuous flow analyser; $\mathrm{A}=$ specific pump operating conditions (see 3.1); $\mathrm{B}=$ specific manifold architecture (see 3.2); $\mathrm{C}=$ more complete exploitation of the recorded signals (see 3.3); ANN = artificial neural networks; MLR = multiple linear regression; PCR = principal component regression; PLS = partial least squares; NA = not available information. 


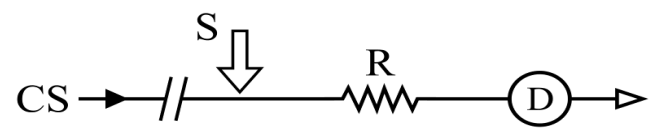

Fig. (1). Didactic representation of a typical flow system exploiting zone stopping. $\mathrm{S}=$ sample; $\mathrm{CS}=$ reagent carrier stream; $\mathrm{R}=$ reactor; $\mathrm{D}=$ detector; solid arrows $=$ sites where pumping is applied; $\|=$ intermittent pumping. For setting up the manifold, see ref. [3].

It should be recalled that the feasibility of zone stopping at the detector without switching the pump on was recently demonstrated [23], and exploitation of this possibility to implement differential reaction-rate methods in flow analysis is recommended.

\subsection{Specific Manifold Architectures}

As a consequence of the high versatility of the flow system, different strategies for implementing reaction-rate methods exploiting specific manifold architectures have been proposed, as discussed further.

\subsubsection{Stream splitting}

The main carrier stream is split, promoting the division of the sample zone; each portion of the sample zone is thereafter transported by a different emergent stream. The emergent streams can be merged together before reaching a single detector or, otherwise, directed towards different detectors.

Regarding stream splitting / stream merging, the sample is inserted into the carrier stream, and the originated sample zone flows through the confluence site b (Fig. 2, upper) where the split process takes place. The resulting emergent streams flow through two parallel reactors. As the splitting process is generally determined by the hydrodynamic pressures involved [24], most of the sample carrier stream with the larger sample portion flows through the shorter reactor, whereas the smaller sample portion flows more slowly through the longer reactor. Higher versatility can be attained by placing a computer controlled three-way valve at point b (Fig. 2, upper) to govern the splitting process [25]. At the next confluence site $\mathrm{c}$, the emergent streams leaving the reactors are merged together. As a consequence of the asynchronous zone merging, the sample portion handled in the shorter reactor reaches the detector before the other portion. Due to the zone overlap involved, a complex sample zone is established and monitored. The resulting concentration / time function is characterised by two maximum values. As these values are associated to two mean sample residence times, differential reaction-rate analytical methods are straightforwardly implemented, as demonstrated in the spectrophotometric flow-injection determination of furfural and vanillin involving two peak height measurements [26]. It should be mentioned that better sensitivity can be attained in flow systems with stream splitting / merging by resorting from the confluence configuration: the sample is inserted into a chemically inert carrier stream and the reagent is added by confluence.

In flow systems designed without stream recombination, the emergent streams should be directed towards different detectors (Fig. 2, lower). As both portions of the sample zone are independently handled in parallel channels, sampling rate is improved, as emphasised by Fernandez et al. who compared three manifold architectures for the spectrophotometric determination of cobalt and nickel [27]. The need for two separated detectors can be avoided by letting the separated emergent streams to flow though the analytical and reference cuvettes of a double-beam spectrophotometer; as a consequence of the dominance of single beam instruments in the market, this possibility has been scarcely exploited.
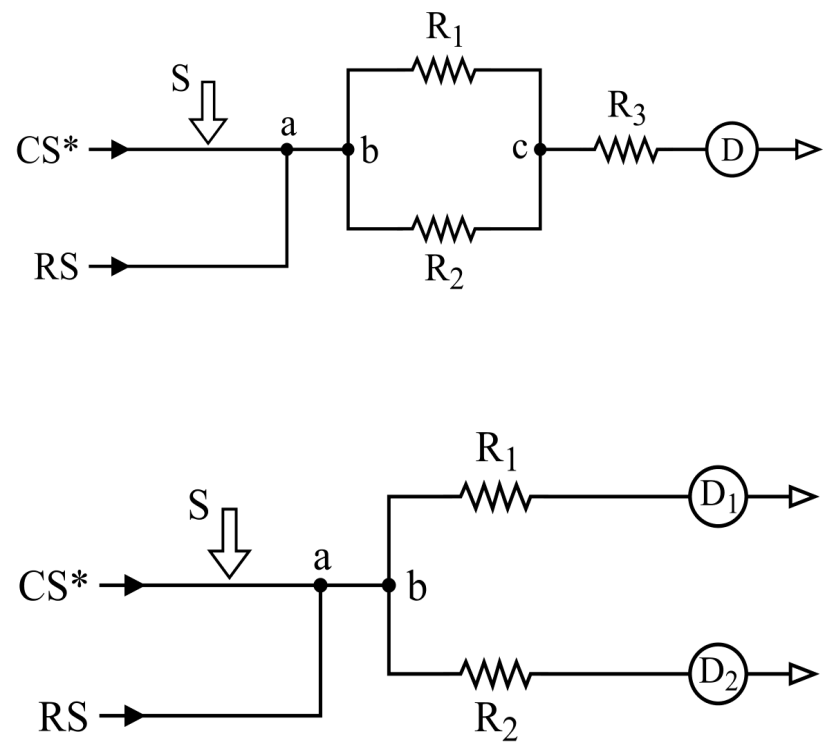

Fig. (2). Didactic representation of flow systems exploiting stream splitting with (upper|) or without (lower) stream merging. $\mathrm{S}=$ sample; $\mathrm{CS}^{*}=$ chemically inert carrier stream; $\mathrm{RS}=$ reagent stream; $\mathrm{a}, \mathrm{b}, \mathrm{c}=$ confluence sites; $\mathrm{R}_{\mathrm{i}}=$ reactors; $\mathrm{D}=$ detector; solid arrows $=$ sites where pumping is applied. For setting up the manifold, see ref. [3].

\subsubsection{Dual Sample Insertion}

Two sample aliquots are simultaneously inserted, originating two sample zones. These aliquots can be inserted into a single carrier stream (Fig. 3, upper) and difference in mean sample residence time into the analytical path is governed by the path length, as both aliquots are inserted at different distances from the detector. This manifold architecture results in a single system, as demonstrated into the determination of $\mathrm{Co}(\mathrm{II})$ and $\mathrm{Ni}(\mathrm{II})$ relying on two serial injection valves [28].

Alternatively, the sample aliquots can be inserted into convergent carrier streams (Fig. 3, lower). Although more complex, the system is characterized by enhanced versatility, as the carrier stream flow rates can be modified at will, and the spectrophotometric determination of $\mathrm{Cu}$ (II) and $\mathrm{Zn}$ (II) in pharmaceutical preparations [29] can be selected as a typical application.

\subsubsection{Reactor Replacement}

The sample aliquot is inserted and the sample zone flows through a relocating reactor. Thereafter, next aliquot is inserted and handled inside a different reactor (Fig. 4). In this way, different sample mean resident times are attained.

The approach is efficiently accomplished by exploiting commutation, as originally demonstrated in the analysis of 
metals [30]. Two different reactors were attached in the central sliding bar of the injector-commuter, so that reactor displacement took place simultaneously with every sample insertion.
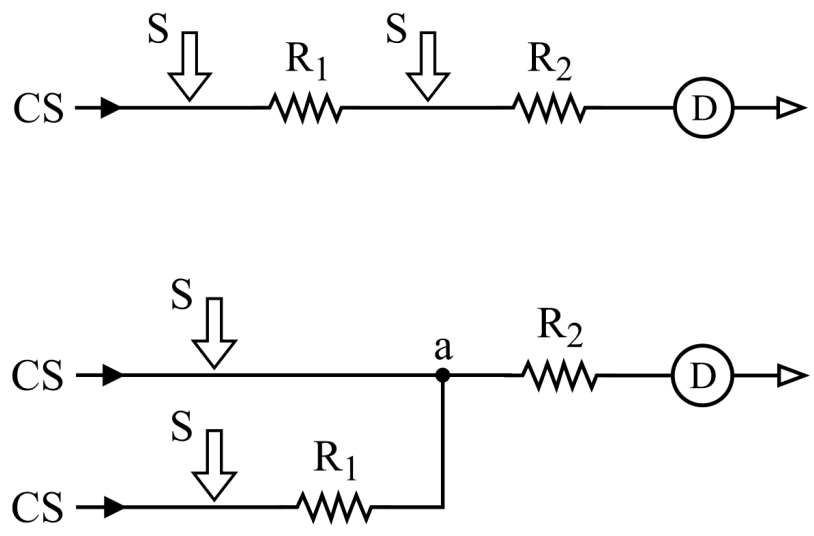

Fig. (3). Didactic representation of flow systems exploiting two sample insertions into a single carrier stream (upper) or into convergent (lower) carrier streams. Symbols as in Figs. $(\mathbf{1}, 2)$. For setting up the manifold, see ref. [3].

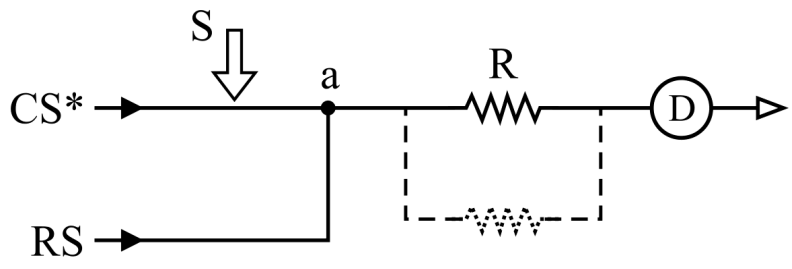

Fig. (4). Didactic representation of a flow system exploiting reactor relocation. Traced lines $=$ alternative reactor position; other symbols as in Figs. $(\mathbf{1}, \mathbf{2})$. For setting up the manifold, see ref. [3].

The innovation can be also implemented without exploiting commutation, as demonstrated in the chemiluminescent determination of ascorbic acid and cysteine in human urine [31]. Kinetic discrimination relied on the rate of ferric ion reduction taking place prior to the sampling loop. In this way, reactor could be manually replaced without the drawbacks associated with repetitive manifold modifications.

\subsubsection{Multi-Site Detection}

The sample aliquot is inserted once and monitored at two different manifold sites.

Initial applications [4] utilized two sequentially positioned flow-through cuvettes (Fig. 5, upper). The need for two detectors can be avoided by resorting from a double beam spectrophotometer (see above), or two flow cells aligned in the same optical beam [32]. A noteworthy feature of this manifold architecture is that the portions of the analytical path after first monitoring site can be heated in order to improve the kinetic discrimination [33]

An advanced manifold can be designed by exploiting multi-commutation in order to permit a single detector to sight at different manifold sites (Fig. 5, lower). The innovation was named as multi-site detection [34]. The flow cell is connected to the central sliding bar of an injectorcommuter and displacement of this bar moves the detector between two sites of the analytical path. The innovation was exploited in the determination of copper and nickel in plant digests [35]. As the complexation of $\mathrm{Ni}(\mathrm{II})$ by the colorforming reagent was relatively slow, the reactor between the monitoring sites was immersed in a warm water bath.
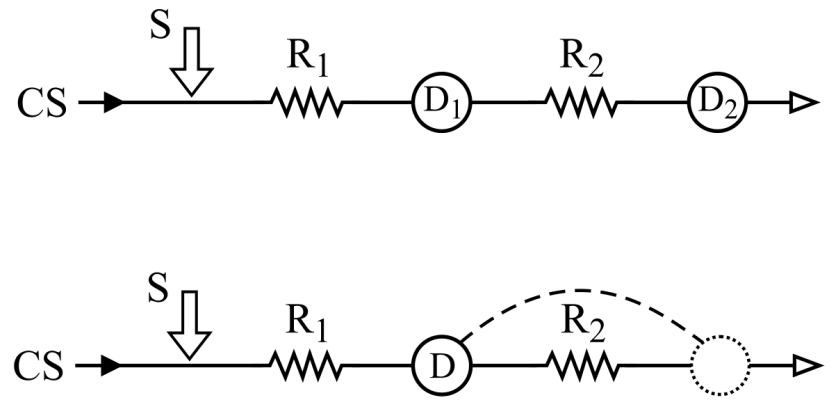

Fig. (5). Didactic representation of flow systems exploiting multi-site detection with separated (upper) or relocating (lower) detectors. Traced lines = alternative detector position; other symbols as in Figs. $(\mathbf{1}, \mathbf{2})$. For setting up the manifold, see ref. [3].

\subsubsection{Other Possibilities}

Other specific manifold architectures exploiting the high versatility of the flow analyzer have been proposed for implementing differential reaction-rate methods.

An interesting approach is to take advantage of sample slicing. One portion of the handled sample zone is stopped into the analytical path whereas the other flows directly towards detection; after a pre-selected time interval, the retained portion is also allowed to flow towards detection; two peaks corresponding to two mean sample residence times are then recorded. The innovation was originally implemented in a sequential injection system and the main rotary valve governed the slicing process, allowing the spectrophotometric determinations of cobalt and nickel in natural waters and soil extracts [36].

Alternatively, flow recycling can be exploited in order to permit the sample zone to be monitored several times under different residence times. The sample is inserted into the main carrier stream and directed towards detection (Fig. 6); thereafter a strategically positioned four-way valve is switched in order to permit the sample zone to recycle, thus to pass several times through the detector; next valve switching directs sample zone towards waste. This specific architecture of the manifold has been considered as a closed loop configuration, and the determination of $\mathrm{Fe}$ (III) and Co(II)in synthetic solutions involving iterative detection by multiple passage of the sample zone through the detector [37] can be selected as a good example to illustrate this potentiality.

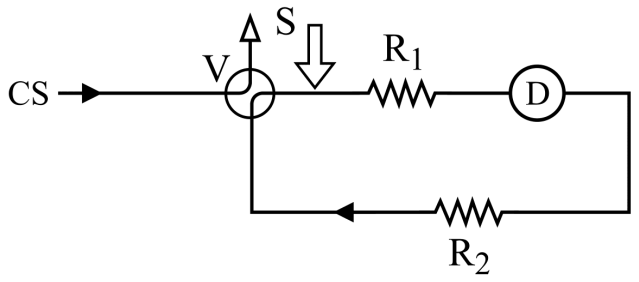

Fig. (6). Didactic representation of a flow system with sample recycling. $\mathrm{V}$ = four-way stream directing valve; other symbols as in Figs. $(\mathbf{1}, \mathbf{2})$. For setting up the manifold, see ref. [3]. 
Regarding segmented flow analysis, different manifold architectures for accomplishing flow reversals or flow recycling were critically compared in relation to the spectrophotometric determinations of L-phenylalanine and L-methionine [38], and good analytical figures of merit were reported for both architectures.

\subsection{Deeper Exploitation of the Recorded Signals}

A deeper exploitation of the recorded signals is performed, allowing the design of a single-line flow system without ON/OFF pump switching, similar to that in Fig. (1) however without zone stopping. Initial attempts to exploit this possibility involved the insertion of a large sample volume into a continuously flowing reagent carrier stream. With a too large sample zone, the analyte / reagent interactions occur predominantly at its front and trailing portions. Passage of the sample zone through the detector results therefore in two peaked signals each one characterized by a different mean sample residence time. The potentialities of this innovation were highlighted in the spectrophotometric flow injection determination of cobalt and nickel exploiting the different rates of analyte complexations with 2-hydroxybenzaldehyde thiosemicarbazone [39].

This innovation was improved by considering multiple measurements performed along the entire flowing sample. Each measurement refers to a given sample residence time, a given sample dispersion and a given sample / reagent volumetric ratio; this is equivalent to exploit multiple pseudo detectors. With multiple data related to different temporal and volumetric conditions, reaction rate methods involving multivariate calibration are straightforwardly implemented, as initially demonstrated in the spectrophotometric determination of iron and vanadium in alloys. The method exploited the influence of $\mathrm{Fe}(\mathrm{II})$ and $\mathrm{V}(\mathrm{IV})$ on the rate of iodide oxidation by $\mathrm{Cr}(\mathrm{VI})$ under acidic conditions; the Jones reducing agent was then needed. Data treatment involved the PLS algorithm.

The analytical procedure was recently improved by avoiding the measurements related to regions of the sample zone with pronounced concentration gradients, as these measurements are intrinsically less reproducible [40]. To this end, different sample aliquots were sequentially inserted into the reagent carrier stream [41], and the resulting zones underwent severe overlap yielding a complex sample zone with regions of maximal and minimal local concentrations. Precise absorbance values associated to these regions were attained.

\section{APPLICATIONS}

Analysis of Table 1 reveals that most applications of differential reaction-rate methods in flow analysis refer to the determination of two (or three) metals or similar organic compounds by spectrophotometry, fluorimetry or chemiluminescence. The potentialities of analytical techniques, especially in simultaneous / sequential determinations, are expanded when implemented in flow analysis, and this aspect is more pronounced in relation to the above mentioned techniques.

The $\left(\mathrm{k}_{1}\left[\mathrm{~A}_{1}\right]\right) /\left(\mathrm{k}_{2}\left[\mathrm{~A}_{2}\right]\right)$ ratio constitutes itself in a limiting factor on the applications of reaction-rate methods, and this limitation is lessened in flow analysis, as the reproducible sample handling, especially timing, is inherent to the analyser.

The number of applications has however decreased in recent years, and two aspects can be highlighted in this context.

- $\quad$ most of the commercially available flow analyzers do not offer facilities for easy implementing differential reaction-rate methods. Consequently most of the users are working in taylor-made systems, normaly in academic laboratories.

- $\quad$ stopped-flow mixing permits an efficient exploitation of ultrafast reactions. However, the required instrumentation is less suitable for large-scale routine analysis.

One expects therefore that this review incentives authors towards a renaissance of this important topic in flow analysis.

\section{TRENDS}

Implementation of differential reaction-rate method in the flow analyser does not modify the general tendencies of flow analysis, especially in regard to downsizing, reduction of waste generation, thus matching the Green Chemistry concept, portability and suitability for routine, often in situ, analyses. One expects an increased exploitation of other kinetic processes such as sequential extractions, sequential sampling, sequential injection chromatography with monolithic columns, etc.

The potentialities of in-line determinations relying on different reaction rates are increased by exploiting different sample handling conditions involving e.g. addition of optional reagents, inter-change of manifold components, use of external energy (heating, UV or ultrasound irradiation) for assisting the analyte discrimination, etc, and these conditions are better established by resorting from concentrationoriented feed-back mechanisms. These tendencies will certainly come true, and preparation of a review article on this theme is highly recommended. Moreover, with the present development of multi-commutation [21], implementation of differential reaction-rate methods in flow analysis will certainly experiment a renaissance.

\section{ACKNOWLEDGEMENTS}

Partial support from the Brazilian agencies FAPESP (proc. \#2011/14413-0) and CNPq (proc. 305378/2011-2) is greatly appreciated.

\section{CONFLICT OF INTEREST}

The authors confirm that this article content has no conflict of interest.

\section{REFERENCES}

[1] Svehla, G.; Perone, S.P.; Cramers, C.A.M.G.; Frei, R.W., van Grieken, R.E.; Klockow, D.; Currie, L.; Ettre, L.S.; Fein, A.; Freiser, H.; Leonard, M.A.; Leyden, D.; Martin, R.F.; Schreiber, B.; Doerffel, K.; Giolito, I.; Grushka, E.; Harris, W.E.; Irving, H.M.N.H.; Jagner, D.; Rosset, W.; Stary, J. Nomenclature of kinetic methods of analysis. Pure Appl. Chem., 1993, 65, 22912298.

[2] Kellner, R.; Mermet, J.-M.; Otto, M.; Widmer, H.M. (Eds), Analytical Chemistry; Wiley VCH: Weinheim, 1998, pp. 227-237. 
[3] Zagatto, E.A.G.; Oliveira, C.C.; Townshend, A.; Worsfold, P.J. Flow Analysis with Spectrophotometric and Luminometric Detection, Elsevier: Amsterdam, 2012.

[4] Dahl, J.H.; Espersen, D.; Jensen, A. Differential kinetic analysis and flow injection analysis. Part 1. The trans-1,2diaminocyclohexane-tetraacetate complexes of magnesium and strontium. Anal. Chim. Acta, 1979, 105, 327-333.

[5] Iida, Y. FIA bibliography (56). J. Flow Injection Anal., 2011, 28, 159-166.

[6] Gervasio, A.P.G.; Fortes, P.R.; Meneses, S.R.P.; Miranda, C.E.S.; Zagatto, E.A.G. An improved flow injection system for spectrophotometric determination of molybdenum and tungsten in tool steels. Talanta, 2006, 69, 927-931.

[7] Mottola, H.A.; Perez-Bendito, D. Kinetic determinations and some kinetic aspects of analytical chemistry. Anal. Chem., 1996, 68, 257R-289R.

[8] Ivaska A., Electrochemical Detection, In: Kolev, S.D.; McKelvie, I.D. Eds., Advances in Flow Injection Analysis and Related Techniques, Wilson and Wilson's Comprehensive Analytical Chemistry, Chapter 16, Elsevier: Amsterdam, 2008, Vol. 54, pp. 441-459.

[9] Beckwith, P.M.; Crouch, S.R. Automated stopped-flow spectrophotometer with digital sequencing for millisecond analyses. Anal. Chem., 1972, 44, 221-227.

[10] Groves, J.T.; Lee, J.-B.; Marla, S.S. Detection and characterization of an oxomanganese(V) porphyrin complex by rapid-mixing stopped-flow spectrophotometry. J. Am. Chem. Soc., 1997, 119, 6269-6273.

[11] Crouch, S.R. Trends in kinetic methods of analysis. Anal. Chim. Acta, 1993, 283, 453-470.

[12] Quencer, B.M.; Crouch, S.R. Multicomponent kinetic methods. Crit. Rev. Anal. Chem., 1993, 24, 243-262.

[13] Wang, J.-H.; He, R.-H. Stopped-flow kinetic spectrophotometric method for the simultaneous determination of iron, titanium and vanadium. Anal. Chim. Acta, 1993, 276, 419-424.

[14] Blanco, M.; Coello, J.; Iturriaga, H.; Maspoch, S.; Riba, J.; Rovira, E. Kinetic spectrophotometric determination of $\mathrm{Ga}$ (III)-Al(III) mixtures by stopped-flow injection analysis using principal component regression. Talanta, 1993, 40, 261-267.

[15] Fortes, P.R.; Meneses, S.R.P.; Zagatto, E.A.G. A novel flow-based strategy for implementing differential kinetic analysis. Anal. Chim. Acta, 2006, 572, 316-320.

[16] Magni, D.M.; Olivieri, A.C.; Bonivardi, A.L. Artificial neural networks study of the catalytic reduction of resazurin: stopped-flow injection kinetic-spectrophotometric determination of $\mathrm{Cu}$ (II) and Ni(II). Anal. Chim. Acta, 2005, 528, 275-284.

[17] Massart, D.L; Vanderginste, B.G.M.; Deming, S.N.; Michotte, Y.; Kaufman, L. Chemometrics: a Textbook. Elsevier: Amsterdam, 1988.

[18] Cullen, T.F.; Crouch, S.R. Multicomponent kinetic determinations using multivariate calibration techniques. Mikrochim. Acta, 1997, 126, 1-9.

[19] Brereton, R.G. Introduction to multivariate calibration in analytical chemistry. Analyst, 2000, 125, 2125-2154.

[20] Ruzicka, J.; Hansen, E.H. Stopped flow and merging zones. A new approach to enzymatic assays by flow injection analysis. Anal. Chim. Acta, 1979, 106, 207-224.

[21] Feres, M.A.; Fortes, P.R.; Zagatto, E.A.G.; Santos, J.L.M.; Lima, J.L.F.C. Multi-commutation in flow analysis: recent developments and applications. Anal. Chim. Acta, 2008, 618, 1-17.

[22] Espinosa-Mansilla, A.; Salinas, F.; Zamoro, A. Simultaneous kinetic determination of chlorpyrifos and carbaryl based on differential degradation process in alkaline oxidative medium. Mikrochim. Acta, 1994, 113, 9-17.

[23] Vida, A.C.F.; Sasaki, M.K.; Gomes, T.F.; Silva, C.R.; Feres, M.A.; Zagatto, E.A.G. Zone trapping / merging zones in flow analysis: a novel approach for rapid assays involving relatively slow chemical reactions. Talanta, 2011, 85, 259-263.

[24] Ruzicka, J.; Stewart, J.W.B.; Zagatto, E.A.G. Flow injection analysis. Part IV. Stream splitting and its application to the continuous spectrophotometric determination of chloride in brackish waters. Anal. Chim. Acta, 1976, 81, 387-398.

[25] Oliveira, C.C.; Sartini, R.P.; Reis, B.F.; Zagatto, E.A.G. Multicommutation in flow analysis. Part 4. Computer-assisted splitting for spectrophotometric determination of copper and zinc in plants. Anal. Chim. Acta, 1996, 332, 173-178.
[26] Linares, P.; Luque de Castro, M.D.; Valcarcel, M. Differential kinetic determination of furfural and vanillin by flow injection analysis. Microchem. J., 1987, 35, 120-124.

[27] Fernandez, A.; Luque de Castro, M.D.; Valcarcel, M. Comparison of flow injection analysis configurations for differential kinetic determination of cobalt and nickel. Anal. Chem., 1984, 56, 11461151.

[28] Fernandez, A.; Luque de Castro, M.D.; Valcarcel, M. Flow injection system for kinetic determinations based on the use of two serial injection valves. Analyst, 1987, 112, 803-807.

[29] Shpigun, L.K.; Shushenachev, Y.V.; Kamilova, P.M. Kinetic separation in flow injection spectrophotometry: Simultaneous determination of copper and zinc in a single run. Anal. Chim. Acta, 2006, 573, 360-365.

[30] Arruda, M.A.Z.; Zagatto, E.A.G.; Maniasso, N. Kinetic determination of cobalt and nickel by flow-injection spectrophotometry. Anal. Chim. Acta, 1993, 283, 476-480.

[31] Li, B.-X.; Wang, D.-M.; Xu, C.-L.; Zhang, Z.-J. Flow-injection simultaneous chemiluminescence determination of ascorbic acid and L-cysteine with partial least squares calibration. Microchim. Acta, 2005, 149, 205-212.

[32] Kuroda, R.; Nara, T.; Oguma, K. Simultaneous determination of iron(III) and total iron by flow injection analysis using kinetic spectrophotometry with tiron. Analyst, 1988, 113, 1557-1560.

[33] Espersen, D.; Jensen, A. Differential kinetic analysis and flow injection analysis. Part II. The (2.2.1) cryptates of magnesium and calcium. Anal. Chim. Acta, 1979, 108, 241-247.

[34] Zagatto, E.A.G.; Bergamin-Filho, H.; Brienza, S.M.B.; Arruda, M.A.Z.; Nogueira, A.R.A.; Lima, J.L.F.C. Multi-site detection in flow analysis. Part 1. Relocation of spectrophotometric detector. Anal. Chim. Acta, 1992, 261, 59-65.

[35] Vendramini, D.; Grassi, V.; Zagatto, E. A. G. Spectrophotometric flow-injection determination of copper and nickel in plant digests exploiting differential kinetic analysis and multi-site detection. Anal. Chim. Acta, 2006, 570, 124-128.

[36] Taljaard, R.E.; van Staden, J.F. Simultaneous determination of cobalt(II) and $\mathrm{Ni}$ (II) in water and soil samples with sequential injection analysis. Anal. Chim. Acta, 1998, 366, 177-186.

[37] Rios, A.; Luque de Castro, M.D.; Valcarcel, M. Simultaneous determination by iterative spectrophotometric detection in a closed flow system. Anal. Chim. Acta, 1986, 179, 463-468.

[38] Hsieh, Y.-S.; Crouch, S.R. Flow reversal and flow recycle airsegmented flow injection for simultaneous determination of a binary mixture. Anal. Chim. Acta, 1995, 304, 333-337.

[39] Fernandez, A.; Luque de Castro, M. D.; Valcarcel, M. Formation of two reaction zones in flow-injection systems for kinetic determinations of cobalt and nickel. Anal. Chim. Acta, 1987, 193, 107-118.

[40] Gisin, M.; Thommen, C.; Mansfield, K.F. Hydrodynamically limited precision of gradient techniques in flow injection analysis. Anal. Chim. Acta, 1986, 179, 149-167.

[41] Fortes, P.R.; Feres, M.A.; Zagatto, E.A.G.; Lima, J.L.F.C. Sequential injections as an alternative to gradient exploitation for implementing differential kinetic analysis in a flow injection system. Talanta, 2010, 81, 1409-1412.

[42] Saurina, J.; Hernandez-Cassou, S. Flow-injection stopped-flow completely continuous flow spectrophotometric determinations of aniline and cyclohexylamine. Anal. Chim. Acta, 1999, 396, 151159.

[43] Alonso-Mateos, A.; Almendral-Parra, M.J.; Fuentes-Prieto, M.S. Sequential and simultaneous determination of bromate and chlorite (DBPs) by flow techniques-Kinetic differentiation. Talanta, 2008, 76, 892-898.

[44] Khalaf, K.D.; Morales-Rubio, A.; Guardia, M.; Garcia, J.M.; Jimenez, F.; Arias, J.J. Simultaneous kinetic determination of carbamate pesticides after derivatization with $p$-aminophenol by using partial least squares. Microchem. J., 1996, 53, 461-471.

[45] Gomez, E.; Cladera, A.; Estela, J.M.; Cerda, V. Multidata treatment applied to the simultaneous resolution of catechol-resorcinol mixtures by kinetic enzymatic processes. Talanta, 1993, 40, 16011607.

[46] Espinosa-Mansilla, A.; Salinas, F.; Zamoro, A. Simultaneous determination of chlorpyrifos and carbaryl by differential degradation using diode-array spectrophotometry optimized by partial least-squares. Analyst, 1994, 119, 1183-1188. 
[47] Li, B.-X; Wang, D.-M.; Lv, J.-G; Zhang, Z.-J. Flow-injection chemiluminescence simultaneous determination of cobalt(II) and copper(II) using partial least squares calibration. Talanta, 2006, 69 , 160-165.

[48] Fernandez, F.M.; Tudino, M.B.; Troccoli, O.E. Multicomponent kinetic determination of $\mathrm{Cu}, \mathrm{Zn}, \mathrm{Co}, \mathrm{Ni}$ and $\mathrm{Fe}$ at trace levels by first and second order multivariate calibration. Anal. Chim. Acta, 2001, 433, 119-134.

[49] Yamane, T.; Ishimizu, C. Simultaneous differential kinetic determination of cobalt and nickel based on on-line complex formation and ligand substitution reaction using a stopped-flow FIA system. Mikrochim. Acta, 1991, 103, 121-129.

[50] Betteridge, D.; Fields, B. Two point kinetic simultaneous determination of cobalt(II) and nickel(II) in aqueous solution using flow injection analysis (FIA), Fresenius Z. Anal. Chem., 1983, 314, 386-390.

[51] Richter, P.; Toral, M.I.; Tapia, A.E.; Ubilla, C.; Bunster, M. Differential kinetics of copper and zinc with zincon in a FIA/stopped flow system. Determination of copper and zinc in brass. Bol. Soc. Chil. Quim., 1996, 41, 167-172.

[52] Shpigun, L.K.; Shushenachev, Y.V.; Kamilova, P.M. Simultaneous spectrophotometric determination of copper(II) and zinc(II) based on their kinetic separation in flow-injection systems. J. Anal. Chem., 2007, 62, 623-631.

[53] Wang, J.-H.; Ruan, W.-J.; He, R.-H. Stopped-flow kinetic determination of a binary mixture: simultaneous determination of europium and cerium. Mikrochim. Acta, 1993, 110, 241-247.

[54] Teixeira, L. S. G.; Costa, A.C.S.; Garrigues, S.; de la Guardia, M. Flow-injection solid phase partial least-squares spectrophotometric simultaneous determination of iron, nickel and zinc. J. Braz. Chem. Soc., 2001, 13, 54-59.

[55] Romero-Saldana, M.; Rios, A.; Luque de Castro, M. D.; Valcarcel, Simple unsegmented flow configurations for simultaneous kinetic determinations. Talanta, 1991, 38, 291-294.

[56] Blanco, M.; Coello, J.; Iturriaga, H.; Maspoch, S.; Redon, M. Artificial neural networks for multicomponent kinetic determinations. Anal. Chem. 1995, 67, 4477-4483.

[57] Havel, J.; Jimenez, F.; Bautista, R.D.; Leon, J.J.A. Evaluation of multicomponent kinetic analysis data by a partial least squares calibration method. Analyst, 1993, 118, 1355-1360.

[58] Blanco, M.; Coello, J.; Iturriaga, H.; Maspoch, S.; Riba, J. Kinetic spectrophotometric method for analyzing mixtures of metal ions by stopped-flow injection analysis using partial least-squares regression. Anal. Chem., 1994, 66, 2905-2911.

[59] Ye, Y.-Z.; Mao, H.-Y.; Chen, Y.-H. Catalytic kinetic simultaneous determination of iron, silver and manganese with the Kalman filter by using flow injection analysis stopped-flow spectrophotometry. Talanta, 1998, 45, 1123-1129.

[60] Wang, J.-H.; He, R.-H. Stopped-flow injection kinetic determination of multicomponent samples: Simultaneous determination of mercury(II) and silver(I). Anal. Chim. Acta, 1994, 294, 195-199.
[61] Shpigun, L.K.; Tsuntsaeva, M.N.; Lunina, V.K.; Zolotov, Y. A.; Prochorova, G.V. Kinetic study and analytical applications of the exchange reactions of lanthanides(III) using flow injection techniques. Anal. Lett., 2001, 34, 1487-1501.

[62] Pistonesi, M.; Centurion, M.E.; Band, B.S.F.; Damiani, P.C.; Olivieri, A.C. Simultaneous determination of levodopa and benserazide by stopped-flow injection analysis and three-way multivariate calibration of kinetic-spectrophotometric data. $J$. Pharm. Biomed. Anal., 2004, 36, 541-547.

[63] Hsieh, Y.-S.; Crouch, S.R. Two-rate method for simultaneous determination of L-amino-acid mixtures. Anal. Chim. Acta, 1994, 296, 333-341.

[64] Maquieira, A.; Luque de Castro, M.D.; Valcarcel, M. Simultaneous enzymatic determination of methanol and ethanol by flow injection analysis. Microchem. J., 1987, 36, 309-315.

[65] Kagenow, H.; Jensen, A. Kinetic determination of magnesium and calcium by stopped-flow injection analysis. Anal. Chim. Acta, 1983, 145, 125-133.

[66] Kagenow, H.; Jensen, A. Differential kinetics analysis and flow injection analysis. Part 3. The (2.2.2) cryptates of magnesium, calcium and strontium. Anal. Chim. Acta, 1980, 114, 227-234.

[67] Lazaro, F.; Luque de Castro, M. D.; Valcarcel, M. Sequential and differential catalytic-fluorimetric determination of manganese and iron by flow injection analysis. Anal. Chim. Acta, 1985, 169, 141148.

[68] Li, B.-X.; He, Y.-Z.; Xu, C.-L. Simultaneous determination of three organophosphorus pesticides residues in vegetables using continuous-flow chemiluminescence with artificial neural network calibration. Talanta, 2007, 72, 223-230.

[69] Guardia, M.; Khalaf, K.D.; Hasan, B.A.; Morales-Rubio, A.; Arias, J.J.; Garcia-Fraga, J.M.; Jimenez, A.I.; Jimenez, F. Simultaneous kinetic spectrophotometric determination of five phenolic compounds by reaction with $p$-aminophenol, using partial least squares data treatment. Analyst, 1996, 121, 1321-1326.

[70] Linares, P.; Luque de Castro, M. D.; Valcarcel, M. Simultaneous determination of pyridoxal and pyridoxal 5-phosphate in humanserum by flow-injection analysis. Anal. Chem., 1985, 57, 21012106.

[71] Li, B.-X.; He, Y.-Z, Lv, J.-G.; Zhang, Z.-J. Simultaneous determination of rifampicin and isoniazid by continuous-flow chemiluminescence with artificial neural network calibration, Anal. Bioanal. Chem., 2005, 383, 817-824.

[72] Linares, P.; Luque de Castro, M.D.; Valcarcel, M. Fluorimetric differential-kinetic determination of silicate and phosphate in waters by flow-injection analysis. Talanta, 1986, 33, 889-893.

[73] Jianhua, W.; Ronghuan, H. Simultaneous determination of a binary mixture - kinetic method for determination of uranium and vanadium. Analusis, 1993, 21, 421-424.

[74] Peng, X.-J.; Mao, Q.-K.; Cheng, J.-K. Simultaneous determination of zinc and mercury with 5,10,15,20-tetrakis(3-chloro-4-sulfophenyl)porphine by differential rate kinetics and flow injection analysis. Fresenius J. Anal. Chem., 1994, 348, 644-647.

This is an open access article licensed under the terms of the Creative Commons Attribution Non-Commercial License (http://creativecommons.org/licenses/by$\mathrm{nc} / 3.0 /$ ) which permits unrestricted, non-commercial use, distribution and reproduction in any medium, provided the work is properly cited. 